\title{
Enterprise - supplier Information Sharing
}

\section{Research Review}

\author{
Jiang Xiaorong \\ Economics and Management Department \\ Xi'an University of Technology (XUT) \\ Xi'an, Shannxi Province,China \\ E-mail: jiaoxiangrong99@163.com
}

\author{
Yang Hui \\ Economics and Management Department \\ Xi'an University of Technology (XUT) \\ Xi'an, Shannxi Province, China \\ E-mail: 304926346@qq.com
}

\begin{abstract}
With the advance of global economic integration and global informatization, manufacturing enterprises are facing the business environment of uncertainty increases gradually, enterprise can only maintain competitive advantage through innovation, thus the survival and development. Manufacturing enterprises, therefore, only to implement information sharing with suppliers, to meet the requirement of manufacturing enterprise innovation, and adapt to the competitive environment. This paper introduces the definition, influence factors of information sharing, laid a solid foundation for future research.
\end{abstract}

Keywords- Information sharing; Innovation performance; Communication; Trust; Commitment

\section{SIGNIFICANCE}

\section{A. Producing hard-copy using MS-Word}

With the arrival of global economic integration and global informatization.Business environment uncertainty companies faced gradually increasing.and the market demand increasingly diversified and personalized .In such an increasingly competitive environment, the enterprise survival and development only through innovation to maintain their own competitive advantage. According to the theory of resource-based view, that depends on the mastery and control of resources and abilities, which is precious,rare,heterogeneous, not to imitate, unique and irreplaceable (Amit \& Schoemaker, 1993; Barney, 1991; Bharadwaj, Varadarajan, \& Fahy, 1993). Resources can be an asset, process, technology, knowledge and information (Barney, 1991; Rajesh Rajaguru, Margaret Jekanyika Matanda, 2012) [1]. So information as the important resource of enterprises to maintain sustainable competitive advantage is indispensable to the development and survival of enterprises.however, development depends on its own internal information resources can not meet the needs of enterprises to maintain a competitive advantage for the information, Therefore, only sharing information with others and choosing valuable to use it reasonably to enable enterprises to adapt to the rapidly changing business environment.
Nowadays, it is a problem can not be ignored in the supply chain. Through information sharing can greatly reduce the cost of each enterprise (Gavirneni Kapuscinski, \& Tayur, 1996; Huang, Lau, \& Mak, 2003; Swaminathan, Sadeh, \& Smith, 1997; Tan, 1999), and get sustainable competitive advantage (Drucker, 1992; Li \& Lin, 2006; Li et al., 2006; Shin, Ishman, \& Sanders, 2007) . Information sharing between each enterprise in the supply chain has become a common practice, it not enhance the competitive advantage of the whole supply chain, but also improve the competitive advantage of various enterprises (Jao-Hong Cheng, 2011) [2]. Especially core firms in the supply chain shoulder the biggest influence of distorted information.Therefore, information sharing in the supply chain is crucial to the development of the manufacturers.it can bring the significant influence for manufacturers to carry out innovation activities, bring direct benefits for manufacturers, such as it can bring significant monetary savings for manufacturers, improve customer service levels, and reduce the inventory cost (Juan r. Trapero, $n$ Kourentzes, r. Fildes, 2012) [3].

\section{INFORMATION SHARING}

\section{A. Definition of information sharing}

Most of the work about information sharing based on Stasser and Titus' s (1985, 1987) biased sampling model,The model shows that groups on the discussion of Shared information(All group members are already known) time spent more than do not share information(information only mastered a group member). Empirical researches on test bias information samples essential to verify the openness -uniqueness dimension of information sharing which described by Hinsz, Tindale, and Vollrath [4]

Jarvenpaa \& Staples (2001) research indicates that information sharing can be an act, like a volunteer provide information to others who need it. Marshall and Bly (2004) definite information sharing behavior is a way to deepen the social contact and the relationship between the message sent and the recipient. Marshall and Bly (2004) focuses on the function and value of information sharing,and they are given three explanations about why 
people are willing to share information to others: (1) the information sender and recipient mutual know; (2) education or training awareness ; (3) To develop friendly relations and promote harmony. Tung-Mou Yang \& Terrence A. Maxwell (2011) consider information sharing is an important way to increase the organizational efficiency and performance [5]. InduShobha ChengalurSmith et al. (2012) noted that information sharing reflects the degree of cooperation and important informationsharing with supply chain partners [6].

Currently, there are many scholars define information sharing form different aspect,but little different, generally,it is defined the sharing of information as among different enterprise information resource exchange and transfer in a particular transaction or cooperation carried out (Ye Fei, Zhang Jie, Lu Hui, 2012) [7].

This paper argues that information sharing is communicated and transferred the high quality of the valuable information between the manufacturer and supplier using of advanced information technology.

\section{B. The influence factors of information sharing}

There are many factors that can affect information sharing in organizations, from Fig .1 and Fig .2, respectively describes the main influence factors within and outside of the organization.

Information sharing between organizations means sharing between buyer and supplier in detail enough,,frequently enough and timely enough to meet the needs of the organization (Humphreys et al., 2004).

Information sharing is defined as personal freedom sharing of information, not just the information that daily transactions between buyers and sellers(Yigitbasioglu and outraged, 2010; Celik et al., 2012; Akshay a. Pujara and Ravi Kant, 2013) .

The following from the perspectives of technology, organization and management to summarize the influence factors of information sharing.

1) The technical perspective

With the development of information technology progress, effectiveness and efficiency of interorganizational cooperation will improve (Zhang and Dawes, 2006). GilGarcia et al. (2007 a) research suggests that information sharing activity can be seen as a information technology projects involving construction of information system, the change of the organizational structure, and business process reengineering .

GilGarcia et al. (2009) study also pointed out that different organizations have different types of hardware and software of information systems, so integrating different platform, data standard, mode and the quality of different information systems is a challenge. Like Web services and service-oriented architecture framework to be used as a bridge between the information systems and inconsistent data structure and definition of heterogeneous databases.

Due to security and confidentiality, Lee and Rao (2007) argue that the use of information technology in information sharing system is a challenge, and it is a vital to design a system which can deal to get authorization and authentication for information sharing .

In addition, the public and private sectors, more and more information systems outsourcing to contractors
(Sullivan and Ngwenyama, 2005). Gonzalez, Gasco, and Llopis (2005) study suggests that outsourcing of information systems also increased the difficulty of crossborder information sharing, because the system design and specification details cannot be written to save;contractors may compete with each other, and some contractors may no longer be in business, information systems can not get timely maintenance and update support.

Akbulut et al. (2009) considers the technical capacity to participate in the organization is another critical factor of cross-border information sharing success ,to overcome technical problems in information sharing can lay a good foundation for information sharing [5].

\section{2) The organization and management perspective}

Dwyer, Schurr, and Oh (1987) study results that information sharing is dependent on the trade-offs including dependence, uncertainty, transaction efficiency, social satisfaction, and so on.

Espinosa et al. (2003) argues that different cultures and time zones pose challenges to information sharing, the distance between the two geographical location can also cause inadequate communication, misunderstandings and conflicts. Navarrete study pointed out (2010) there exist an international border when information sharing activities related to national organizations [8]. Soo Min Toh et al. (2012) also studies suggest that the organizational structure, culture (Kim and Lee, 2006), and various functions (Cresswell et al., 2005) also play an important role in a successful information-sharing activities [9]

Samaddar, Nargundkar, and Daley (2006) studied the consistency of target how to impact information sharing between enterprises.They argue that the degree of same goals that participants sharing information agreed may affect the nature and quantity of knowledge and information they willing to share with others. For example,Samaddar et al. think different interests may increase opportunistic behavior when time when enterprises formed business relationships. In order to alleviate this phenomenon, they advice Target consistency as a management mechanism which maybe lead to a winwin situation (Sharon S. Dawes, Mohammed A. Gharawi, G. Brian Burke, 2012) [10]. And Frazier et al. (2009) found the factors prompted the distributors and suppliers to share information are income, cost, risks, and argued that the perceived risk will be reduced after information shared.

Timon c. Du et al. (2012) study from the perspective of partnership - data - process to discusse the factors that that affect the willingness of companies to share information the study pointed out that trust, cooperation and interdependence is the center of information sharing success (Timon c. Du, Vincent s. Lai et. Al., 2012) [11] .Li and Lin (2006)research suggests that trust and shared vision between supply chain partners have a positive impact on information sharing and information quality, but the uncertainty of suppliers have a negative impact on them. Top management has a positive impact on information sharing, but no effect on the quality of the information. The results also show that information quality and information sharing can not affected on the uncertainty of customer, technical uncertainty, commitment of supply chain partners and information technology (IT) promoters (Akshay a. Pujara and Ravi Kant, 2013). Ye Fei et al. (2011) took an investigation about trust, they investigated 189 
manufacturing enterprises in Guangdong Pearl River Delta region, and studied that relationship between trust and information sharing, in which trust can be divided into two dimensions: the ability to trust and emotional trust. The results indicated that there was a significant positive correlation between emotional trust and information sharing, and the relationship between the ability to trust and information sharing is not significant [12].

Jao-Hong Cheng (2011) proposed a research model to test the role of the relationship interests of the organization, relationship orientation, connectivity, power symmetry and the negative conflict. An important finding was that because of the relationship benefits and interorganizational connectivity, information sharing and negative conflict were positively correlated. The relationship interests impact on organizations information sharing between through its positive impact on connectivity trends and relationships. On the contrary, the relationship sinterest also affected information sharing by its negatively impact on the symmetry of the power.The results of study provide useful insight, to improve information sharing between organizations, supply chain members how to strengthen their behaviors and activities of relationship interests andconnectivity cooperation [2].

\section{The dimension of information sharing}

Lee et al (2000) provided information content can be shared in the study, and noted that among supply chain companies can share five categories of information, such as inventory levels, sales levels, forecast information, order information and production or delivery information .Li et al. (2006) put forward in the study can be shared including trading information, operations, and strategic information, etc .Above all scholars studied information sharing from the aspect of shared content, Zhou et al. (2007) measure it from the support technology of information sharing , information content and information quality three aspects ; YeFei et al. (2012) researched shared content and information quality to metric information sharing [7].

According to the research foundation of the above scholars and the research objective of this article, The following measure information sharing from the quality of information, information content and information technology three aspects.

\section{1) The quality of information}

There is no generally accepted standard definition about information quality. Common definition is:how information user satisfied with information .Through the study, Wang et al. (1996) found there are 15 information quality dimensions can be used to measure it, scholars put them into four types: respectively the inherent information quality (including accuracy, objectivity, credibility, and reliability of information), the correlated information quality (including relevance,completeness, valueadded,right amount and timeliness of information), express information quality (including understandability, simplicity, explanation and consistency of information), and quality of access to information (including accessibility and security of information).Kahn (1997) defined information quality from the perspective of the data: information meet the requirements of specification[13].
Salaun and Flores (2001) emphasized information quality refers to the degree of satisfaction of the user's interest and novelty.Other requirement attribute refers to the extent of the appropriate update, as well as information accessibility and understandability.Another important aspect of information quality is practicability, accuracy, reliability, reduce uncertainty, clear objectives, and timeliness (Power and Sohal, 2001; Hong, Doll and Nahm, 2004; SunHee Youn, Paul Hong * and Abraham Nahm, 2008) [14]. Particularly information funcations such as the accuracy, reliability and availability is closely related to logistics activities in the supply chain .(Gustin et al., 1995). The importance of information quality in supply chain management has been discussed in many studies (eg Rabren, 2010; Ramayah and Omar, 2010; Li et al 2006; Miller 2005; Raghunathan, 1999; Monczka et al, 1998; Gustin et al., 1995). The quality of the exchanged information between customers and suppliers(MasonJones, 1997, Monzcka et al., 1998; Holmberg, 2000; Forslund and Jonsson, 2007) is an important part of the successful operation of the organization(Miller, 2005; Li et al., 2006). In order to improve performance, managers need high-quality information to make business and tactics or strategy decisions,Effective information sharing depends on what information to share, how to share information, with whom to share information,each piece of information in the supply chain have a different purpose (Holmberg, 2000).

Monczka et al. (1998) emphasized that information quality should cover the exchanged information accuracy, timeliness, adequacy and credibility elements. Similar properties in $\mathrm{Li}$ and $\mathrm{Lin}$ (2006), Li et al. (2006), Forslund and Jonsson (2007) study is used to measure information quality. Moberg et al. (2002) measure information quality with attributions such as timeliness, accuracy, completeness, adequacy and credibility. However, Miller (2005) measure it based on the accuracy , credibility ,objectivity, reliability, relevance, timeliness, integrity, information, understandability, consistency, simplicity, format and appearance, accessibility, safety and availability of information quality. These attributes apply to service productions, supply of tangible products. Lack of communication and poor information quality seem to have an impact on the effectiveness and efficiency of supply chain performance (Roaimah Omar et al., 2010) [15].

\section{2) The information content}

Information has a wide range, it can be Shared within the company and throughout the supply chain. According to the needs of the organization, the market, product, design, processing, production, pricing, planning, inventory, logistics, demand forecasting, order, sales promotion strategy, customer demand, production planning, allocation of work, technical know-how, manufacturing method and the sales forecast and other relevant information can be shared with supply chain partners (e.g. Yu et al., 2001; Zhang et al., 2006; Ramayah and Omar, 2010).According to the different levels of decisionmaking on the supply chain, information sharing can be divided into strategic, tactical and business level. Device configuration decisions are devided into strategic supply chain decisions and tactical supply chain 
decisions.production / distribution planning, capacity allocation, inventory allocation, outsourcing and security of supply chain inventory decision Belong to the latter. On the other hand, order supplement and transportation decisions as a business supply chain decision (Huang.et.al.,2003).

About information sharing content, foreign scholars mostly research from the aspects of sharing demand information, inventory information and other information and get a relatively large number of research results.this paper summarizes the results of their study are shown in Table 4.

TABLE I. THE SUMMARY OF EXISTING RESEARCH ABOUT INFORMATION SHARING

\begin{tabular}{|c|c|c|}
\hline Classification & Researchers & $\begin{array}{c}\begin{array}{c}\text { Research content and main } \\
\text { contribution }\end{array} \\
\end{array}$ \\
\hline \multirow{5}{*}{$\begin{array}{l}\text { Sharing } \\
\text { demand } \\
\text { information }\end{array}$} & Lee(1997) & $\begin{array}{l}\text { Research,With the method of data } \\
\text { modeling research, give four reasons } \\
\text { lead to the phenomenon of "bullwhip } \\
\text { effect". }\end{array}$ \\
\hline & Chen(2000) & $\begin{array}{l}\text { Quantitative study two factors of } \\
\text { cause of "bullwhip effect", namely, } \\
\text { demand forecast and Order } \\
\text { preparation,research } \\
\text { thatfocusing on customer demand } \\
\text { information can reduce the "bullwhip } \\
\text { effect" }\end{array}$ \\
\hline & $\begin{array}{l}\text { Lummus(199 } \\
\text { 9) }\end{array}$ & $\begin{array}{l}\text { Examined the effect of information } \\
\text { sharing on supply chain management } \\
\text { performance in the multi-agent } \\
\text { simulation experiments. }\end{array}$ \\
\hline & $\begin{array}{l}\text { Thonemann( } \\
\text { 2002) }\end{array}$ & $\begin{array}{l}\text { Analyzed how advanced demand } \\
\text { information sharing to improve the } \\
\text { performance of supply chain } \\
\text { management. }\end{array}$ \\
\hline & $\begin{array}{l}\text { Xiande } \\
\text { Zhao(2002) }\end{array}$ & $\begin{array}{l}\text { Using simulation method to study } \\
\text { how choosing demand forecasting } \\
\text { model affect on information sharing } \\
\text { and supply chain performance ina } \\
\text { secondary supply composed of one } \\
\text { supplier and multiple retailers. }\end{array}$ \\
\hline \multirow{3}{*}{$\begin{array}{l}\text { Sharing } \\
\text { inventory } \\
\text { information }\end{array}$} & $\begin{array}{l}\text { Gavirneni(19 } \\
\text { 99) }\end{array}$ & $\begin{array}{l}\text { The two-stage supply chain } \\
\text { inventory as the research object, } \\
\text { analyzed supplier's earnings in case } \\
\text { of the information is not Sharng, } \\
\text { parts of sharing and fully Sharing. }\end{array}$ \\
\hline & $\begin{array}{l}\operatorname{Machuca}(20 \\
04)\end{array}$ & $\begin{array}{l}\text { Using the simulator based on Web } \\
\text { technology to verify potential } \\
\text { benefits that come from the use of } \\
\text { electronic data interchange (EDI) } \\
\text { technology in supply chain } \\
\text { management. }\end{array}$ \\
\hline & $\begin{array}{l}\text { Gavirneni(20 } \\
06)\end{array}$ & $\begin{array}{l}\text { Considering secondary supply chain } \\
\text { composed of a supplier with general } \\
\text { production capacity and a retailer } \\
\text { faced with an independent and } \\
\text { identically distributed end-user } \\
\text { needs,suppliers can improve the } \\
\text { performance of the supply chain } \\
\text { through price changes. }\end{array}$ \\
\hline \multirow{2}{*}{$\begin{array}{l}\text { Sharing other } \\
\text { information }\end{array}$} & Raju(2000) & $\begin{array}{l}\text { Using game theory model analysis of } \\
\text { the characteristics of the enterprise } \\
\text { and industry is how to reduce the } \\
\text { information impact on profits. }\end{array}$ \\
\hline & Barut(2002) & $\begin{array}{l}\text { two aspects, information density and } \\
\text { the breadth, provide a measure of } \\
\text { coupling degree of supply chain } \\
\text { model, then using the model to test } \\
\text { an enterprise in what way or how to } \\
\text { better sharing with other members in }\end{array}$ \\
\hline
\end{tabular}

\begin{tabular}{|l|l|l|}
\hline & $\begin{array}{l}\text { the supply chain from the } \\
\text { perspective of information system }\end{array}$ \\
\cline { 2 - 3 } & $\begin{array}{l}\text { Researched information sharing } \\
\text { policies between organizations how } \\
\text { Li(2006) } \\
\text { to affect business performance in } \\
\text { market environment stability and } \\
\text { rapid changed. }\end{array}$ \\
\hline \multirow{2}{*}{$\begin{array}{l}\text { Samaddar(20 } \\
06)\end{array}$} & $\begin{array}{l}\text { Developed a theoretical framework } \\
\text { model can be used to investigate } \\
\text { relevant relationship of supply chain } \\
\text { network design and information } \\
\text { sharing between organizations. }\end{array}$ \\
\hline
\end{tabular}

\section{3) Information technology (IT)}

The process of information sharing needs the support of IT, currently, IT is considered to be the main driver of supply chain management. St John et al. (2001) and Vickery et al. (2003) suggests that the problem of supply chain management is not arising now, but using information tools to get accurate, timely and reasonable information is not easy to achieve.Bowersox and Calantone (1998) argued that supply chain management requires a lot of information systems and those system have functions of data management, and be able to obtain advanced information between organizations in time.Patterson et al. (2004) argue that supply chain management is rely on information, information is vital to the success of supply chain management, so managers need to be good at applying and developing advanced IT technology, IT technology including throughout whole supply chain ,it can be used to collect and analyze information, and then according to the results of the analysisto implement tactics of hardware, software and manpower, etc. [16].

Roaimah Omar and Ramayah T. et al (2010) [15] suggest that between manufacturers and suppliers can apply information technologies including EDI (Electronic Data Interchange), Internet, Extranet , EPT (electronic funds transfer), DRP (distribution Requirements Planning), SRM (supplier Relationship Management), VMI (vendor Managed Inventory), DW (data warehouse) and SCM software (supply chain management software).

\section{The value of information sharing}

Many scholars researches found that information sharing can reduce inventory costs in the first place. For example, Cachon and Fisher (2000), and Lee, et al. (2000) analysis the real-time demand information sharing between suppliers and customers and revenue of inventory levels by investing sharing between one supplier and multiple retailers, found that information sharing can significantly save time, reduce inventory and cost savings [16] [3]. Xiaolong Xue et al. (2011) discussed value of sharing in different enterprise inventory policies under the situation of supplier does provide the supply information or not, compared the value of information sharing in different inventory policies, found that information sharing can improve the overall level of service contractors and reduce the total cost of inventory when the general contractor selected an inventory policy[17]

Pandey et al. (2010) verify the effect of different types of information sharing on competitive advantage of Indian manufacturers. They found that information sharing for manufacturers to win the order parameter, namely to the 
competitive advantage of cost benefit and service level has a significant impact. Information sharing is an important means to improve customer relationships. It can improve the resource use of buyers, the output, and flexibility performance. The scope of information sharing between buyers and major suppliers depends on the degree of uncertainty and interdependence of the information (Yigitbasioglu and outraged, 2010). When the capacity information strictly limited to relatively average demand, information is more valuable. With the increase of capacity, the value of information gradually weaken, because the supplier can meet the needs of retailers, and additional capacity will help to conceal the impact of poor quality decisions. (Helper et al., 2010; Akshay a. Pujara and Ravi Kant, 2013) .

Information sharing for the enterprise to forecast and plan also has a certain value. Mohammad m. li et al. (2012) analyzed prediction precision under retailers and manufacturers information sharing, analysis contained two situations: predicted-information sharing or not

In no information sharing, retailers do not share any information with manufacturers, however, the latter organization prediction is based on the former order. On the contrary, in the case of forecasting information sharing, sharing predictions to each other . Orders the latter group send to suppliers based on these Shared predictions. By calculating the accuracy of the prediction, inventory and inventory cost to compare the two methods. In addition, the results shown that it has a great potential to improve the prediction precision for secondary supply chain ,namely retailers and manufacturers [18].

the results show that information sharing is always beneficial for manufacturers, manufacturers can determine the optimal wholesale price and achieve their maximum profit through information sharing. However, from the perspective of the supply chain system profit maximization, common decision coordination is better than information sharing coordination [18].

Appropriate information sharing strategy has a significant effect for information sharing, because it can reduce the uncertainty of supply chain(Hung et al., 2011).

The same, information sharing is a key factor in supply chain management. The type of information required depends on the supply chain problems can be solved. Zhou and Benton (2007) studied the relationship between the effective supply chain practice and information sharing,found that, effective supply chain practice improved with the increase of level of information sharing .

The supply chain approximation formed with quality expectations method and the information sharing between buyers and suppliers have a positive impact on the building of a strategic alliance (Narasimhan and Nair, 2005). Shahin and Robinson (2002) measure the value of information sharing and coordination between system through strategic. Experimental results show that a traditional supply chain move to a fully integrated system can reduce the cost of $47.58 \%$. Yee (2005) simulated the affect of demand structure of information sharing on supply chain performance, the simulation results indicated that the demand structure can determine the best generation of supply chain performance .

\section{ACKNOWLEDGMENT}

This thesis is funded by science and technology project of Xi'an City(SF1408-3).

\section{REFERENCES}

[1] Rajaguru r., Matanda m. J.. The Effects of Intel - organizational compatibility on supply chain "capabilities: Exploring the mediating role of Intel - organizational information systems integration (IOIS) [J]. Industrial Marketing Management, 2012, 1 to 13 .

[2] Cheng relationship. Intel - organizational relationships and information sharing in supply chains [J]. International Journal of information Management, 2011, 31:374-384.

[3] Juan r. Trapero, N., r. Kourentzes Fildes. The Impact of information exchange on: supplier forecasting performance [J]. Omega, 2012, 40, 738-747.

[4] Jessica r. Magnus m., Leslie a. DeChurch. The Information Sharing and Team Performance: A Meta - Analysis [J]. Journal of Applied tended, 2009, 94 (2) : 535-546.

[5] Yang T.M., Terrence a. Maxwell. Information - sharing in public organizations: A literature review of interpersonal, intra organizational and Intel - organizational success factors [J]. Journal of Government Information Quarterly, 2011, 28:164-175.

[6] Peter Duchessi [23] InduShobha Chengalur - Smith, j. Ramon Gil Garcia. Information sharing and business systems, leveraging the in supply chains: An empirical study of one web - -based application [J]. Information \& Management, 2012,49:58-67.

[7] Titiyeah Zhang Jie, Lv Hui. Supplier opportunism behavior effects on information sharing and operations performance $[\mathrm{J}]$. Journal of management science, 2012, 25 (2) : 51 to 60 .

[8] Yang T.M., Zheng 1., Pardo T.. The boundaries of information sharing and integration: A case study of Taiwan e - Government [J]. Journal of Governm ent information Quarterly,,49:2012 S51 - S60.

[9] Toh s.m, Srinivas E.S.. Perceptions of task cohesiveness and organizational support happens trust and information sharing between the host country nationals and expatriate co - workers in Oman [J]. Journal of World Business, 2012,47:696-705.

[10] Dawes, s. s. Gharawi bioarchaeology, Burke G.B.. Transnational public sector knowledge networks, knowledge and information sharing in a multi - dimensional context [J]. Journal of Gover nment information Quarterly, 2012, 29: S112 - S120.

[11] Du t.c., Lai V.S., Cheung, W., et al. The Willingness to share information in a supply chain: a partnership - data - the process perspective [J]. Information \& Management, 2012,49:89-98.

[12] Titiyeah, kai, Lv Hui et al. Executives personal ties to suppliers of information sharing mechanism study of trust between organizations as agents [J]. Journal of management science, and science and technology, 2011, 32 (6) : 140-149.

[13] Yew fai. Under the network environment based on user experience and perception of information quality influencing factors of empirical research [D]. Tianjin normal university, 2012.

[14] Youn s., Hong p. and Nahm A.. Supply chain partnerships and Supply chain intergration: the mediating role of information quality and sharing [J]. Int. J Logistics Systems and Management, 2008, 4 (4) : 437-456.

[15] Omar r. Ramayah t., Lo McCain, et al., Information sharing, Information quality and the usage of Information technology (IT) tools in Malaysian organizations [J]. Journal of substitutes -- -- the Business Management, 2010, 4 (12) : 2486-2499.

[16] Song Fuling. Environmental uncertainty of trust and information sharing between supply chain enterprises GuaXi adjustment research [D]. Jilin university, 2012.

[17] Yan R.L.. Demand forecast information sharing in the competitive online and traditional retailers [J]. Journal of Retailing and Consumer Services, 2010:386-394.

[18] Ali M.M. Boylan, j. e. Syntetos A.A.. Forecast errors and the inventory performance under Forecast information sharing [J]. International Journal of Forecasting, 2012, 28:830-841. 